\title{
THE USE OF SIMULATION AND DESIGN OF EXPERIMENTS FOR PRODUCTIVITY IMPROVEMENT IN THE SAWMILL INDUSTRY
}

\author{
Felipe F. Baesler \\ Eduardo Araya \\ Francisco J. Ramis \\ Department of Industrial Engineering \\ University of Bio-Bio \\ Av. Collao 1202, Casilla 5-C \\ Concepción, CHILE
}

\author{
José A. Sepúlveda \\ Department of Industrial Engineering \\ and Management Systems \\ University of Central Florida \\ P.O. Box 162450 \\ Orlando, FL 32816-2450, U.S.A.
}

\begin{abstract}
This work presents a discrete event simulation model of an important sawmill in Chile. This model was used to perform a bottleneck analysis of the wood process and to propose, based on these results, alternatives that would yield to an improvement in the process productivity. Different alternatives were simulated and the results obtained were used to perform a full factorial design in order to select the combination of factors that have the most important impact in the process productivity. The implementation of these improvement measures could increase the wood production up to a $25 \%$.
\end{abstract}

\section{INTRODUCTION}

The paper presents the use of experimental design and simulation to identify the main variables affecting the productivity at an automated large sawmill having a production capacity of 20,000 cubic meters per month. One of the main characteristics of this sawmill is that it has optimization capacities in the first cut, second cut and edger machines, with scanners previous to all these machines.

Modern sawmills are capital intensive facilities designed to maximize the recovery of wood out of the logs. They are complex systems, with many sources of variability, such changing demand, non-homogenous raw material, machine breakdowns and different production options, that makes them very attractive to be studied using simulation, to maximize their productivity and efficiency.

Many examples can be found in the literature where the use of simulation in the forest industry is reported. Brunner, Funck and Zhang (1994) presents one of the earliest paper using object orientation for sawmill simulation. Wenjie et Al. (1995) reports on modeling different products through simulation. Dogan, Mclain and Wicklun (1997) applies simulation to a hardwood mill and Kyle and
Ludka (2000) the use of simulation in the furniture industry. Baesler, Moraga and Ramis (2002), reports on the use of simulation and artificial intelligence techniques to improve productivity in a wood industry, and Ramis et Al. (2004), use simulation to identify and eliminate bottlenecks at a sawmill. This paper takes full advantages of experimental design and simulation to identify and to weight the importance of different variables in the operation of a sawmill, in order to improve the productivity of the mill.

\section{SYSTEM DESCRIPTION}

In general terms, in Figure 1 it is shown the process that follow the logs to become timber with final dimensions. The logs are loaded into a conveyor, and then they go into a positioning machine and a true shape scanner to determine the optimal way to produce the first cut at the first machine. This cut is done at a sharp chain type machine with optimization capacities, a chipper canter and two band saws. The first cut produces lateral wood (which is used for furniture and moldings), a semi-log, which goes into a second cut at a multi rip machine and chips which goes to pulp mills, see Figure 2. If the laterals produced are double, they have to pass through a horizontal resaw before going into the edger machines. The second cut produce additional lateral wood and a flitch from the central part of the log. The lateral wood goes into the edgers to give the final width to the lumber and the flitch goes into a multi rip gang to produce lumber. At the end of the model, two conveyors take the lumber into a sorter.

From a schematic point of view, a sawmill is a collection of conveyors, which takes the logs or lumber through different machines, until they get the final dimensions.

\subsection{Simulation Model}

A simulation model using Automod was constructed. A sawmill is a very singular process in comparison to other 


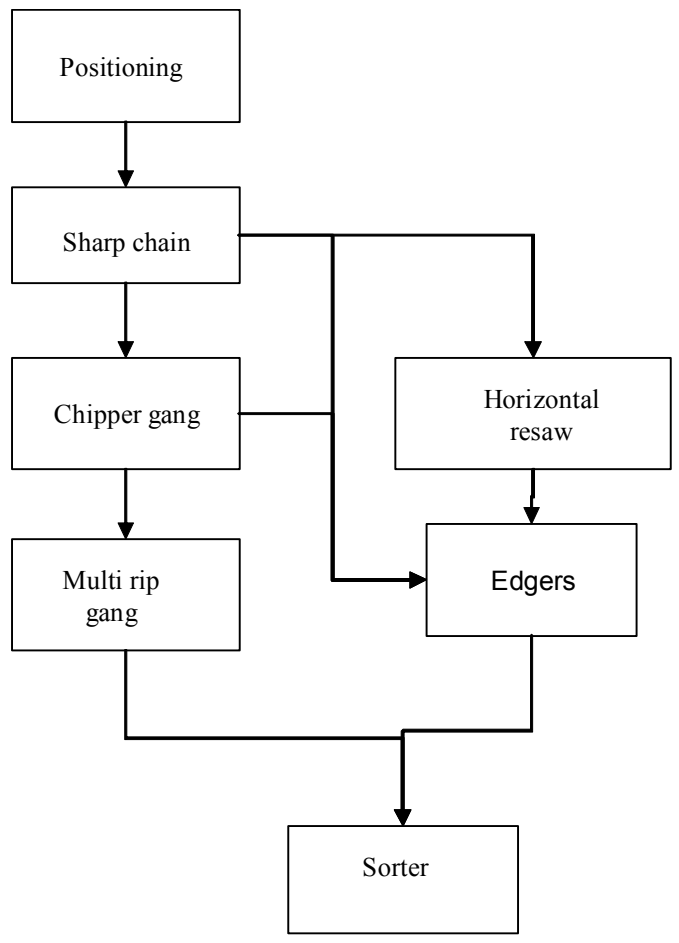

Figure 1: Process Flow

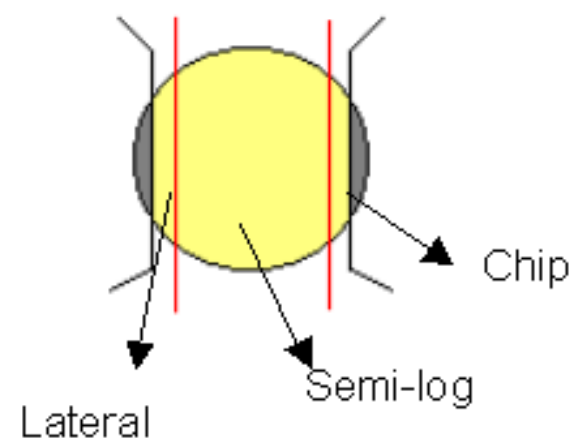

Figure 2: Cutting Diagram of the First Cut

industries. Machine processing time is considered zero, because the logs pass through the machine based on the conveyor's speed. This way the whole process is a continues conveyor with different saw machine that are synchronized with the parts movement. Since machine processing time is zero, no source of randomness is associated to machines and the system could be modeled in a deterministic way. Even though this is true, there are other sources of randomness, such as machine failures and logs diameter variability. The system is fed with logs with a target diameter, in this problem a 29 centimeters diameter was considered. Even though, this is the desired diameter, exist variability on the distribution of diameters that arrives into the system. This issue is very important since the sawmill optimizes the wood utilization based on the logs diameters. This is done performing changes on the saws position in some machines, what generates setup time. In other words, if just one diameter were used, no setup time would be necessary. All this information was gathered using databases and doing on site data collection and then analyzed for inclusion into the model. Finally, a statistical and face validation was done, concluding that the simulation model is a good representation of the real system.

\subsection{Methodology}

The main objective of the simulation model was the bottleneck detection. This task was done analyzing the utilization of the different machines in the process. The results show that the main bottleneck is the Sharp Chain, which corresponds to the second machine in the system. This machine has the highest utilization factor as well as been the machine responsible for stopping the system with more frequency due to the long queues of logs waiting to be process. The second bottleneck detected was the Canter machine. This resource becomes the bottleneck after solving the problem in the Circular Saw. In order to analyze improvement opportunities in the system, a design of experiments study was conducted considering four main factors that may have an impact in the performance of these machines. The measure of effectiveness selected was the system's productivity (logs/day). The factors considered for analysis are:

- Diametric dispersion decreased. This factor considers a change in the characteristics of the logs that feeds the system. The second machine, the circular saw, performs changes in the position of their cutting saws depending on the logs diameter. This setup time can be lowered if the logs diameter that are fed into the system is more homogenic. This example was performed using a target diameter of 29 centimeters with a dispersion of 5-10-70-10-5. These numbers represent the percentage of the diameters 27-28-29-30-31, which is available for processing.

- Wood extractions. About $50 \%$ of the wood does not need to pass through the Canter machine. One alternative is to detour this wood using a bypass conveyor that already exists. This way the load of this machine can be decreased.

- Circular saw speed increased. Even though the speed of this machine depends on the logs diameter, exists an alternative of increasing the speed without changing the objective diameter. This can be done using a different cutting diagram.

- Positioning machine. This factor considers decreasing the time required for positioning the logs in this machine. This is perfectly feasible, since this step is a manual process that can be improved introducing changes in the procedures used by the operator for the logs positioning. 
This information was used to construct a two level full factorial experimental design. This type of design requires a total of $2 \mathrm{k}$ experiments, where $\mathrm{k}$ is the number of factors included in the analysis. The Table 1 shows the high and low level for each factor.

Table 1: Factor Levels

\begin{tabular}{|c|cc|}
\hline Factor & Low (-) & High (+) \\
\hline A & No & Yes \\
B & $5-10-70-10-5$ & $5-90-5$ \\
C & 50 & 60 \\
D & Normal & Normal $-1 \mathrm{~s}$ \\
\hline
\end{tabular}

Where

A: Wood Extractions

B: Diametric dispersion (\% based on diameters 27-28-2930-31)

C: Second machine speed (meters per second)

D: Positioning time (seconds). High level considers a decrease of 1 second in the positioning time.

Table 2 shows the results of the 16 experiments required for the study. Each scenario was simulated for 90 hours and 10 replications.

Table 2: Scenarios Results

\begin{tabular}{|c|c|c|c|c|c|c|}
\hline & $\mathbf{A}$ & $\mathbf{B}$ & $\mathbf{C}$ & $\mathbf{D}$ & Logs processed & \% of increase \\
\hline $\mathbf{1}$ & & - & - & - & 19.228 & ------ \\
\hline $\mathbf{2}$ & + & - & - & - & 20.701 & $7,7 \%$ \\
\hline $\mathbf{3}$ & - & + & - & - & 19.149 & $-0,4 \%$ \\
\hline $\mathbf{4}$ & + & + & - & - & 22.571 & $17,4 \%$ \\
\hline $\mathbf{5}$ & - & - & + & - & 19.246 & $0,1 \%$ \\
\hline $\mathbf{6}$ & + & - & + & - & 22.155 & $15,2 \%$ \\
\hline $\mathbf{7}$ & - & + & + & - & 19.372 & $0,7 \%$ \\
\hline $\mathbf{8}$ & + & + & + & - & 22.549 & $17,3 \%$ \\
\hline $\mathbf{9}$ & - & - & - & + & 19.143 & $-0,4 \%$ \\
\hline $\mathbf{1 0}$ & + & - & - & + & 20.433 & $6,3 \%$ \\
\hline $\mathbf{1 1}$ & - & + & - & + & 19.392 & $0,9 \%$ \\
\hline $\mathbf{1 2}$ & + & + & - & + & 24.042 & $25,0 \%$ \\
\hline $\mathbf{1 3}$ & - & - & + & + & 19.474 & $1,3 \%$ \\
\hline $\mathbf{1 4}$ & + & - & + & + & 22.799 & $18,6 \%$ \\
\hline $\mathbf{1 5}$ & - & + & + & + & 19.485 & $1,3 \%$ \\
\hline $\mathbf{1 6}$ & + & + & + & + & 24.485 & $27,3 \%$ \\
\hline
\end{tabular}

Figure 3 presents the Pareto chart for this analysis. This chart shows the statistical significance for each individual factor and two-way interactions. The chart shows that the main factor A (wood extractions) has the most important individual effect followed by factor B. The main factors $\mathrm{C}$ and $\mathrm{D}$, have no effect in the analysis. The chart also shows that the two-way interaction $\mathrm{AB}$ is the only one that has statistical significance.

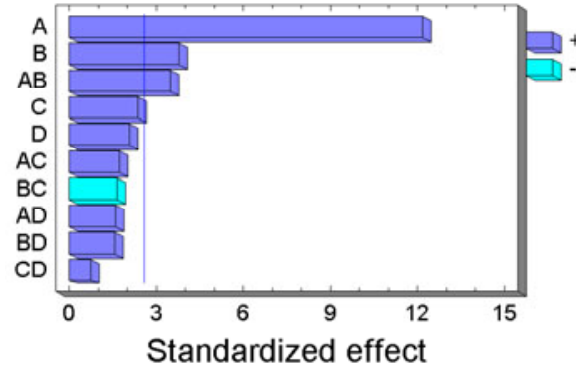

Figure 3: Pareto Chart

\section{ANALYSIS OF RESULTS}

The analysis permits to conclude that the factors A and B should be set in the high position. Now it is important to analyze how the factors $\mathrm{C}$ and $\mathrm{D}$ must be set in order to maximize the system's performance. The Figure 4 presents a response surface plot showing the effect of factors $\mathrm{C}$ and $\mathrm{D}$ with the factors $\mathrm{A}$ and $\mathrm{B}$ fixed in high position.

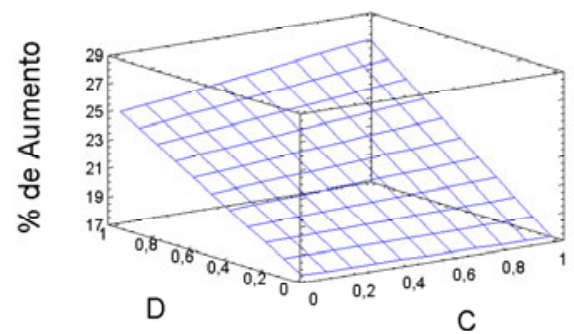

Figure 4: Response Surface Plot

The plot shows that factor $\mathrm{D}$ has an important effect versus factor $\mathrm{C}$. This means that the three-way interaction ABD is suggested. In order to define the exact level that the factor D has to be set, a contour map was constructed and presented in Figure 5. The plot shows that if factor $\mathrm{C}$ is set in low, the maximum effect is obtained setting factor $\mathrm{D}$ in an $86 \%$. This means that it is not necessary to set factor $\mathrm{D}$ in it maximum position, since the same effect is obtained with just an $86 \%$ of increased. This combination permits to increase the production in approximately $25 \%$.

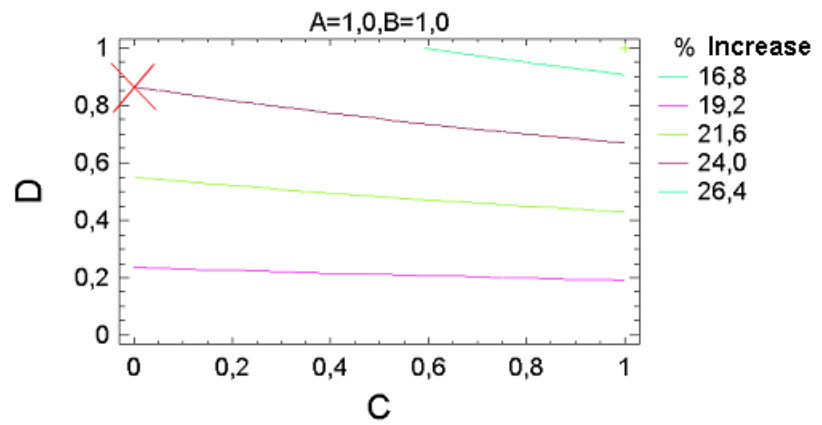

Figure 5: Contour Map 


\section{CONCLUSIONS}

This article shows how simulation and design of experiments can be used for analyzing improvement opportunities in the sawmill industry. The analysis showed that it is possible to increase a $25 \%$ the system productivity by applying minor changes in the operational conditions of the sawmill. The next step in this study is to perform a more detailed analysis applying other types of designs and an optimization using response surface methodology.

\section{REFERENCES}

Baesler, F., M. Moraga and F. Ramis, 2002. Productivity improvement in the wood industry using Simulation and artificial intelligence, In Proceedings of the 2002 Winter Simulation Conference, eds. E. Yücesan, C.-H. Chen, J. L. Snowdon, and J. M. Charnes, 1095-1098. Piscataway, New Jersey: Institute of Electrical and Electronics Engineers.

Brunner, Ch., J. Funck and G. Zhang, 1994. Discrete-event object-oriented modeling environment for sawmill simulation. Simulation, 62(2):119-130.

Dogan, C. A., T. F. McClain and S. Wicklund, 1997. Simulation modeling and analysis of a hardwood sawmill. Simulation Practice and Theory, 5(5): 387-403.

Kyle, R. G. and C. R. Ludka. 2000. Simulating the furniture industry. In Proceedings of the 2000 Winter Simulation Conference, eds. J. A. Joines, R. R. Barton, K. Kang, and P. A. Fishwick, 1347 -1350. Piscataway, New Jersey: Institute of Electrical and Electronics Engineers.

Ramis, F, R. Jarpa, J. Palma, J. M. Sánchez, F. Baesler and J. Sepúlveda, 2004. Bottleneck Analysis using simulation. American Institute of Industrial Engineering, In Proceedings of Simulation Solutions 2004, Orlando.

Wenjie, L., D. Earl Kline, Ph. A. Araman and J. K. Wiedenbeck, 1995. Design and Evaluation of Log-toDimension Manufacturing Systems Using System Simulation. Forest Products Journal, 45(3):37-44.

\section{AUTHOR BIOGRAPHIES}

FELIPE F. BAESLER is an Assistant Professor of Industrial Engineering at Universidad del Bio-Bio in Concepción Chile. He received his Ph.D. from University of Central Florida in 2000. His research interests are in Simulation Optimization and Artificial Intelligence. His email <fbaesler@ubiobio.cl>

EDUARDO ARAYA is a Field Engineer at Universidad del Bío-Bio. He received his I.E degree from Universidad del Bio-Bio in 2003. His e-mail is <eduaraya@ubobio. cl>.

FRANCISCO J. RAMIS is an Associate Professor of Industrial Engineering at Universidad del Bio-Bio in Concep- ción Chile. He received his Ph.D. from Georgia Tech in 1985. His research interests are in Process Innovation, Economic Decision Analysis and Simulation. His e-mail is <framis@ubiobio.cl>.

JOSÉ A. SEPÚLVEDA is Associate Professor in the Department of Industrial Engineering and Management Systems Department at the University of Central Florida. He received his Ingeniero Civil Químico degree from the Universidad Santa María, Valparaíso, Chile, in 1970. From the University of Pittsburgh he received a M. S. degree in Industrial Engineering in 1972, a Master in Public Health degree in 1974, and a Ph.D. degree in Industrial Engineering in 1981. Dr. Sepúlveda is a registered Professional Engineer in Florida (1983) and Chile (1975). He is a member of the Institute of Industrial Engineers, the Society for Computer Simulation, the Institute of Management Sciences, the American Public Health Association, and the Hospital Information Management Systems Society. His email address is <mailto: sepulved@mail.ucf.edu>. 